\title{
Medical Education in Islamic Countries A Proposal for the Future
}

\author{
Dr. Kaj O. Werneman, M.D. \\ Dr. Joan M. Werneman, CCRN, Ed.D.
}

DOI: http://dx.doi.org/10.5915/18-3_4-12804

\begin{abstract}
:
Medical school programs in Islamic countries are usually "imports" from the Western world without adequate adaption to the Muslim society. This article is meant to show a way to deal with this dilemma. An emphasis is placed on program development integrating Islmaic principles and basic medical education.
\end{abstract}

KEY WORDS: Medical Education, Islamic Values, Program Development

For the most part, medical school programs in developing countries have been transported from developed countries with inadequate adaptation to the needs of the receiving countries. It is essential that medical school programs be developed within the context of a given country according to its cultural beliefs, attitudes and values. In order to promote changes in health those factors must be reflected in the curriculum.

Thus the concept of a medical school program in Muslim countries based on Islamic values would be to "...bring spiritual and material matters together in perfect harmony, both in its values and in its attitude..." This is what Islam represents according to Dr. Abdel-Aziz El Sayed, former Director-General of the Arab League Educational, Scientific and Cultural Organization. We are not talking about having courses in Islamic Studies within the curriculum, but an integration of Islamic concepts running throughout all course material taught. This is known as a curriculum thread which is a recurring idea or concept that would span the curriculum, increasing in depth and strength as the student progresses in the program.

The principles of Islam would add to the supporting curriculum structure by providing a dimension spanning the entire program. This curriculum thread would support the relevant program content and help expand the student's basic knowledge of Islam. The thread would need to permeate the course objectives in the syllabus and be evident in the classroom as well as in the clinical area.

There are several alternatives for the implementation of such a concept; one is the establishment of a new program whereby one would need to look at the many elements that are desirable components of program and curriculum development. These principle

King Abdulaziz University Hospital

P. O. Box 6615

Jeddah, Saudi Arabia are universally applicable to all programs, be they a Medical, Nursing, Dietetic, etc. program. The program has to be built on a firm base in order to succeed. Another alternative would be the restructuring of a curriculum at an already existing program.

When you are developing a new program many factors need to be taken into consideration according to Dr. Carol Peterson, Professor at South Dakota State University. ${ }^{2}$ The first step is a feasibility study whereby you would:

1. Review the community health needs affecting need for health services;

2. Make a study of the available resources: institutional, clinical, financial, human;

3. Know the philosophy and context of the academic institution in which the program will exist;

4. Determine the type and level of the program to be developed;

5. Make a study of the meeds and characteristics of potential students.

The next step is the Design Phase in which you would need to:

1. Write the philosophical-conceptual framework; including the philosophy of the program, conceptual framework, philosophy of teaching and learning;

2. Analysis of the philosophical-conceptual framework to yield major concepts and subconcepts and major influences on outline and sequence of curriculum;

3. Develop the competencies; analysis of real world of practice, identification of competencies, validation of competencies by practitioners;

4. The competencies are then screened, expanded, refined, organized using philosophicalconceptual framework; 
5. Outline an overall structural plan of curriculum reflecting the conceptual framework, competencies, philosophy of teaching-learning, practical academic realities, an understanding of the systems model applied to curriculum.

Afterwhich you have the Development Phase, then the Implementation and Evaluation Phases. The Development Phase consist of the substrucutre of the curriculum, which includes:

1. Analysis of competencies to yield terminal and supporting performance objectives;

2. Clarification of blueprint of content reflecting necessary knowledge, skills, attitudes needed to get to the specified cometencies;

3. Clarifying blocks of content - ie., courses, units, modules;

4. Determining teaching-learning experiences and strategies appropriate to blueprint of content;

5. Writing more specific instructional objectives as needed;

6. Preparing teaching-learning materials or designing teaching-learning experiences.

The above statements have emphasized the phases of program development. In addition, there are specific aspects of program development that need to be mentioned.

In the initial development of any program it is wise to start with the description of the occupation, job function, ultimate role in the clinical setting, services provided and major areas of responsibility. This is the base of curriculum development of any new education program.

1. The program objectives should:

1.1 Include an outline of educational commitments to the students.

1.2 Include a set of descriptions of the graduate's job entry level competencies.

1.3 Be reflected in course objectives, learning experiences provided and methods of evaluation.

2. The program must demonstrate the relationship between a quality education process and the policies of admission, content of the curriculum, instructional methods and procedures, quality of work required of the students and requirements for graduation.

3. Planning and implementation of the educational program should include a conceptual model utilised as a base for curriculum design. This needs to be stated in the proposal.

4. Performance objectives for all phases of curriculum and for graduation shall be clearly defined in terms of measurable behaviour and included in the proposal to give total insight into the

\section{program.}

5. A program description and its contents, including organization of the program, admission procedures, entrance requirements, information concerning facilities and settings used for the clinical experience, learning goals, course objectives and competencies to be attained.

6. A structured curriculum which combines clinical education with clearly written course syllabi describing learning and competency objectives. Stating purpose, course objectives, content and methods of student evaluation.

7. List of resources available. Resources must be adequate to support the number of students admitted to the program. Enough equipment, supplies and faculty should be available to the program to assure meeting the educational goals for the students. The number of students is dependent upon the availability of equipment, supplies, and clinical staff and course load.

8. Listing of clinical objectives for each phase in the form of Terminal Performance Objectives.

9. A written affiliation agreement between the University and each clinical facility must be established in order to define clearly the extent of the commitment and division of responsibility.

10. Methods, procedures and instruments for evaluating, assessing and measuring the efficacy of the program objectives and student learnig need to be included in the curriculum. A process for periodic and systematic review of the program's effectiveness needs to be written into the proposal. The program director needs to develop a written plan describing the mechanisms to be used to evaluate the effectiveness of the program. Significant aspects may be assessed through questionnaires, surveys, interviews or other means with faculty, students, graduates of the program, and employers of the graduates. The latter is a very important element of this evaluation; that is evidence of follow up of the graduates of the program.

The Prophet had said, "Acquire knowledge. It enableth its possessor to distinguish right from wrong; it lighteth the way to heaven; it is our friend in the desert, our society in solitude, our companion when friendless; it guideth us to happiness, it sustaineth us in misery; it is an ornament amongst friends and armor against enemies." ${ }^{3}$ What better way to acquire knowledge in the Medical profession than to do so based on Islamic principles.

\section{References}

1. El Sayed, Abdel Aziz. "Science and the Islamic World: Comment." Impact of Science on Society, 1976, Vol. 26, No. 3, 123-31. 
2. Peterson, Carol. "Blueprint for Curriculum Development: A Comprehensive View." Curriculum Development and its Implementation Through a Conceptual Framework, 1978, No.
23-1723, 1-18.

3. Gulick, Robert L., "Muhammad the Educator". Lahore: Institute of Islamic Culture, 1975. 